\title{
Socio-economic status is related to incidence of asthma and respiratory
} symptoms in adults

\author{
U. Hedlund**\#, K. Eriksson" and E. Rönmark*,
}

ABSTRACT: The aim of the present study was to assess the association between socio-economic status and impaired respiratory health in a 10-yr follow-up of a population-based postal survey in Northern Sweden.

Multiple logistic regression was used to estimate odds ratios in relation to socio-economic class, using age, sex, a family history of asthma, smoking habits, and occupational exposures to dust, gases and fumes as possible confounders.

The study comprised 2,341 males and 2,413 females. Cumulative incidences were generally lowest in professionals, including executives and civil servants at intermediate and higher levels, who were chosen as reference group. Manual workers in industry showed a significantly increased risk of developing asthma, recurrent wheeze, attacks of shortness of breath or a combination of the two, and chronic productive cough. Manual workers in service showed a similar pattern for attacks of shortness of breath, recurrent wheeze, or a combination of the two, and chronic productive cough. The corresponding population attributable risks were $\sim 10 \%$.

Low socio-economic status was a risk factor for the development of asthma, symptoms common in asthma and chronic productive cough.

\section{KEYWORDS: Asthma, incidence, occupational epidemiology, respiratory symptoms}

$\mathbf{M}$ ost disease, and poor health in general, is associated with low socio-economic status, particularly in Scandinavian countries [1]. In contrast, asthma has been recognised as a disease common in middle and upper socio-economic classes (SECs). This has recently been questioned [2]. Diverging results for the relation of asthma to socio-economic status have been published, some demonstrating more asthma with high socio-economic status [3, $4]$, and others showing the opposite $[5,6]$, or no preference regarding socio-economic status $[7,8]$. Most of these studies have examined children and adolescents, typically using a cross-sectional design. Only one single-cohort study based on a general population sample of adults has evaluated the relationship between socio-economic status and asthma [9]. EAGAN et al. [9] found that incidence of asthma and symptoms common in asthma are strongly related to low educational level. Another large-scale study of adolescents and young adults in four cities in the USA also found that low educational level is associated with increased incidence of asthma [10].

Socio-economic status may be used in order to stratify subjects in society. In epidemiological studies, classification of socio-economic status usually includes income, occupation and occupational status, and educational level, or a combination of these $[9,11]$.

The Obstructive Lung Disease in Northern Sweden Studies include longitudinal studies of several cohorts. The first cohort was recruited in 1985-1986 [12], and a follow-up study was performed in $1996[13,14]$. The aim of the present study was to assess the relationship between socio-economic status and incidence of asthma and respiratory symptoms. Adjustments were made for possible confounders, including occupations in which exposure to dust, gases or fumes are common.

\section{MATERIAL AND METHODS}

The first postal questionnaire survey was performed during the period December 1985-March 1986 [12], and the follow-up study was performed 10 yrs later, during the winter of 1996 [13, 14]. The studies were approved by the ethics committee of Umeå University (Umeå, Sweden).

\section{Study population}

The first survey included all of the 6,610 people born during 1919-1920, 1934-1935 and 1949-1950

\section{AFFILIATIONS}

*The Obstructive Lung Disease in Northern Sweden Studies, Dept of Medicine, Sunderby Central Hospital of Norrbotten, Luleå,

${ }^{\#}$ Occupational Medicine, Dept of Public Health and Clinical Medicine, Umeå University, Umeå, and

"Lung and Allergy Research, National Institute of Environmental Medicine, Karolinska Institute, Stockholm, Sweden.

\section{CORRESPONDENCE}

E. Rönmark

Lung and Allergy Research

National Institute of Environmental

Medicine

Karolinska Institute

SE-17177 Stockholm

Sweden

Fax: 46920230843

E-mail: eva.ronmark@telia.com

Received:

September 142005

Accepted after revision:

March 082006

\section{SUPPORT STATEMENT}

This study was supported by the Swedish Heart-Lung Foundation (Stockholm), the Swedish AsthmaAllergy Foundation (Stockholm), and the local health authority in Norrbotten (Luleå, Sweden). 
and living in eight representative areas of the northernmost province of Sweden, Norrbotten, which covers a quarter of the total area of Sweden. The participation rate was $86 \%$ [12].

During the 10-yr follow-up period, the mortality rate was high among the elderly. In the oldest age group, 30\% of males and $16 \%$ of females had died. In total, 574 subjects within the cohort had died, 99 had moved abroad and four could not be traced. The study population thus comprised 5,933 subjects in 1996. During the performance of the present study, an additional 13 individuals died, 26 suffered from severe medical conditions and two moved abroad. In 1996, completed questionnaires were received from 5,189 of the 5,892 (88\%) remaining subjects, or $83 \%(4,754)$ of the subjects who participated in the first survey in 1986.

\section{Methods}

The same questionnaire was used in the two surveys. The questionnaire was developed from a revised version [15] of the UK Medical Research Council questionnaire [16], and has been used in other Swedish and international studies [17]. The questions about respiratory symptoms and diseases included the following: recurrent wheeze, attacks of shortness of breath, long-standing cough, sputum production, chronic productive cough, asthma, allergic rhinitis, chronic bronchitis or emphysema, and use of asthma medicines. In addition, the questionnaire included questions about smoking habits, occupation and family history of obstructive airway diseases. Following the surveys in 1986 and 1996, the asthma diagnosis reported in the questionnaire (physician-diagnosed asthma) has been clinically validated using a structured interview and methacholine test $[14,18]$, to which $90 \%$ of the methacholinetested incident cases of physician-diagnosed asthma reacted [14].

\section{Socio-economic classification}

The socio-economic classification system that was used has been developed by Statistics Sweden [19], and is based on occupation, divided into categories as follows: 1) manual workers in industry: occupations involving production of goods and normally requiring $\leqslant 2$ yrs of post-comprehensive school education; 2) manual workers in service: occupations involving service production and normally requiring $\leqslant 2$ yrs of post-comprehensive school education; 3) assistant nonmanual employees: non-manual occupations normally requiring $\leqslant 2 \mathrm{yrs}$ of post-comprehensive school education; 4) professionals, including executives and civil servants at high and intermediate level: occupations requiring $\geqslant 3 \mathrm{yrs}$ of university or college education; 5) housewives or their male equivalents: subjects who work in their own households with no other indicator of SEC; 6) self-employed: the non-professional self-employed, including small- and large-scale entrepreneurs and farmers; and 7) unclear: subjects with unclear or no information according to the above groups. Subjects who were retired were classified by their last occupational title.

\section{Other definitions}

Asthma was classified according to the question "Have you been diagnosed as having asthma by a doctor?" (physiciandiagnosed asthma). The question about use of asthma medicines was as follows: "Do you currently use asthma medicines (permanently or as needed)?", and is described in the text as "asthma medicines".

Wheezing was classified according to the question "Do you usually have wheezing, whistling, or a noisy sound in your chest when breathing?" (i.e. recurrent wheeze).

Attacks of shortness of breath were classified according to the question: "Do you now have or have you had asthma symptoms during the last 10 yrs (intermittent breathlessness or attacks of shortness of breath; the symptoms may exist simultaneously with or without cough or wheezing)?"

Asthmatic symptom complex was classified on the basis of the combination of positive answers regarding both attacks of shortness of breath and wheezing [20].

Sputum production was classified according to the question "Do you usually have phlegm when coughing, or do you have phlegm on your chest, which is difficult to bring up?"

Chronic productive cough was classified according to the question "Do you bring up phlegm when coughing on most days during periods of at least 3 months during at least 2 successive years?"

Subjects who currently smoked or had stopped smoking within 12 months prior to the study were classified as smokers, whereas those who had stopped smoking $>12$ months before the onset of the study were classified as ex-smokers. Smoking habits were divided into seven smoking categories describing the changes in smoking habits during the follow-up period. The subjects were further classified into those with or without an occupation, in 1986 and 1996, respectively, in which exposure to dust, gases or fumes were common. This classification was based on the Nordic Classification on Occupation [21].

\section{Analyses}

The cumulative incidence was defined as the proportion of subjects without the studied condition at the start of the followup period who developed this condition during the period under study. The calculations were based on the two surveys, expressing a 10-yr cumulative incidence. The population attributable risk was calculated as $\mathrm{p}\left(\mathrm{OR}_{\mathrm{Exp}}-1\right) / \mathrm{OR}_{\mathrm{Exp}}$, where $\mathrm{OR}_{\mathrm{Exp}}$ is the odds ratio in the exposed group (i.e. SEC) and $\mathrm{p}$ the fraction of exposed subjects among cases [22].

The Chi-squared test was used for bivariate calculations. The $5 \%$ level was considered significant. The incidence of asthma and symptoms were calculated by 1986 SEC among those who remained within the same SEC during the follow-up period and among those who changed SEC during the study, respectively.

Determinants for incident cases of asthma and symptoms were calculated by multiple logistic regression analysis, and the risks were expressed as odds ratios (ORs) with 95\% confidence intervals (CIs). These analyses were also based on 1986 SEC and performed separately among those who remained within the same SEC throughout the study and among those who changed SEC, respectively. Since no significant differences between SECs were found among those who had changed SEC during the observation period, the results regarding incidence 
and risks are given by 1986 SEC. The additional independent variables other than SEC used in the model were age, sex, family history of asthma, smoking habits, and occupations in which exposure to dust, gases, or fumes are common. Paired interactions between different SECs and the other independent variables were examined using $p<0.01$ as the level of significance in order not to increase the $\alpha$ error.

\section{RESULTS}

\section{Demography}

Manual workers represented the largest socio-economic group among both males $(50 \%)$ and females $(39 \%)$, whereas professionals comprised $23 \%$ of males and $17 \%$ of females. The majority of the cohort $(66 \%)$ remained within the same SEC throughout the study (table 1).

The great majority among both males (80\%) and females $(84 \%)$ had stable smoking habits throughout the 10-yr follow-up period. Smoking habits and change in smoking habits were unequally distributed among the SECs (table 2). Persistent smokers were most common among manual workers and assistant non-manual employees, and least common among professionals. Never smoking was most common among housewives.

\section{Prevalence and cumulative incidence}

The prevalence of all of the studied variables increased significantly between 1986 and 1996 (fig. 1). The 10-yr cumulative incidence of asthma was $6.2 \%$, chronic productive cough $6.9 \%$, asthma medicines $9.2 \%$, and symptoms used in the analyses $10-12 \%$ (table 3 ). The incidence of asthma, asthma medicines, wheezing and attacks of shortness of breath were all significantly higher among females, and, by SEC, the incidence was highest among groups dominated by females. Of the incident cases of asthma, $96 \%$ reported attacks of shortness of breath, $72 \%$ wheeze, $28 \%$ chronic productive cough and $91 \%$ use of asthma medicines.

\section{Socio-economic group}

The SEC professionals showed the lowest incidence of asthma and most symptoms, and were therefore used as the reference group when calculating risks. Manual workers in industry exhibited an increased risk of developing asthma (OR 1.7; 95\% CI 1.0-2.7). This increased risk was supported by increased risks of symptoms common in asthma: wheezing (OR 1.7; 95\% CI 1.1-2.6), attacks of shortness of breath (OR 1.7 (95\% CI 1.22.4 ), and a combination of the two, the asthmatic symptom complex (OR 1.9; 95\% CI 1.2-3.1). Further, manual work in industry was also associated with incident chronic productive cough (OR 1.7; 95\% CI 1.1-2.7) (table 3).

Manual workers in service showed a significantly increased risk of developing wheeze, attacks of shortness of breath, the asthmatic symptom complex, chronic productive cough and use of asthma medicines, with odds ratios ranging 1.4-1.8 (table 3).

The SECs assistant non-manual employees and housewives were not significantly associated with the development of any symptom or condition, and the SEC self-employed nonprofessionals were significantly associated only with incident attacks of shortness of breath.

Significant interaction was found between SEC and age for sputum production $(\mathrm{p}=0.001)$. In the elderly, increased risks were found for manual workers in industry (OR 2.6; 95\% CI 1.4-5.0), manual workers in service (OR 2.1; 95\% CI 1.2-3.9), assistant non-manual employees (OR 3.5; 95\% CI 1.6-7.2) and professionals (OR 2.3; 95\% CI 1.1-4.9).

Corresponding analyses were also performed including only persistent nonsmokers and excluding the oldest age group. The results were consistent with those of the analyses above, although, due to smaller numbers in the group, the power in the statistical analysis was affected.

Corresponding analyses were performed based on prevalent cases in 1986. In contrast, manual workers in industry were not associated with an increased risk of asthma or respiratory symptoms, whereas manual workers in service were associated with increased risks of attacks of shortness of breath (OR 1.6; 95\% CI 1.1-2.2) and wheezing (OR 1.4; 95\% CI 1.0-1.9). Assistant non-manual employees showed an increased risk of developing asthma (OR 1.6; 95\% CI 1.1-2.5) (table 4).

TABLE 1 Socio-economic class (SEC) by sex and age in 1986 study population

\begin{tabular}{|c|c|c|c|c|c|}
\hline & \multirow[t]{2}{*}{ Males } & \multirow[t]{2}{*}{ Females } & \multicolumn{2}{|c|}{ Age yrs } & \multirow{2}{*}{$\begin{array}{c}\text { Same SEC in } 1996 \\
\%\end{array}$} \\
\hline & & & Males & Females & \\
\hline Manual workers in industry & $885(38,92)$ & $80(3.3,8.3)$ & $48 \pm 11$ & $50 \pm 11$ & 79 \\
\hline Manual workers in service & $228(12,25)$ & $856(36,75)$ & $47 \pm 12$ & $49 \pm 11$ & 81 \\
\hline Assistant non-manual employees & $314(13,42)$ & $437(18,58)$ & $49 \pm 11$ & $45 \pm 9.0$ & 61 \\
\hline Self-employed & $118(5.0,59)$ & $81(3.4,41)$ & $50 \pm 12$ & $47 \pm 12$ & 39 \\
\hline Unclear & $195(8.3,38)$ & $321(13,62)$ & $60 \pm 11$ & $62 \pm 10$ & 8.9 \\
\hline Total & $2341(100,49)$ & $2413(100,51)$ & $48 \pm 12$ & $49 \pm 12$ & 66 \\
\hline
\end{tabular}

Data are presented as $n$ (percentage of same sex, percentage of subjects in this SEC) or mean \pm SD, unless otherwise indicated. ${ }^{\#}$ : No calculations performed for cells with $<5$ subjects. 
TABLE 2 Smoking habits 1986-1996 by 1986 socio-economic class

\begin{tabular}{|c|c|c|c|c|c|c|c|}
\hline \multicolumn{7}{|c|}{ Smoking habits $1986-1996 \%$} & \multirow{2}{*}{$\begin{array}{c}\text { Unchanged } \\
\text { smoking habits } \\
\text { 1986-1996 } \\
\%\end{array}$} \\
\hline $\begin{array}{l}\text { Persistent } \\
\text { nonsmokers }\end{array}$ & $\begin{array}{l}\text { Persistent } \\
\text { ex-smokers }\end{array}$ & $\begin{array}{c}\text { Persistent } \\
\text { smokers }\end{array}$ & Starters & Re-starters & Quitters & Unclear & \\
\hline
\end{tabular}

\begin{tabular}{|c|c|c|c|c|c|c|c|c|}
\hline Manual workers in industry & 32 & 29 & 21 & 0.4 & 1.9 & 14 & 1.2 & 82 \\
\hline Professionals & 40 & 29 & 17 & 0.6 & 1.6 & 11 & 1.1 & 86 \\
\hline Self-employed & 41 & 26 & 19 & 1.5 & 0 & 11 & 1.5 & 86 \\
\hline Unknown & 50 & 21 & 11 & 0.4 & 0.6 & 7.6 & 9.9 & 82 \\
\hline Total & 40 & 25 & 19 & 0.5 & 1.6 & 11 & 2.4 & 84 \\
\hline
\end{tabular}

\section{Population attributable risk}

The population attributable risk of manual workers in industry for the incidence of asthma, attacks of shortness of breath, wheezing, asthmatic symptom complex and chronic productive cough ranged 8.9-11. With the exception of asthma, this was also found for manual workers in service, ranging 7.6-12 (table 5).

\section{Other risk factors}

The major risk factor for incident asthma was a family history of asthma (OR 3.9; 95\% CI 3.0-5.0). Also, female sex (OR 1.5; 95\% CI 1.1-2.1) and being persistent ex-smokers (OR 2.0; 95\% CI 1.5-2.8) and quitters (OR 2.0; 95\% CI 1.4-3.0) were associated with incident asthma (table 6).

A family history of asthma was significantly associated with the incidence of all analysed symptoms and incident users of asthma medicines, yielding ORs ranging 1.6-2.9. Female sex was also significantly associated with incident users of asthma medicines and attacks of shortness of breath. Persistent

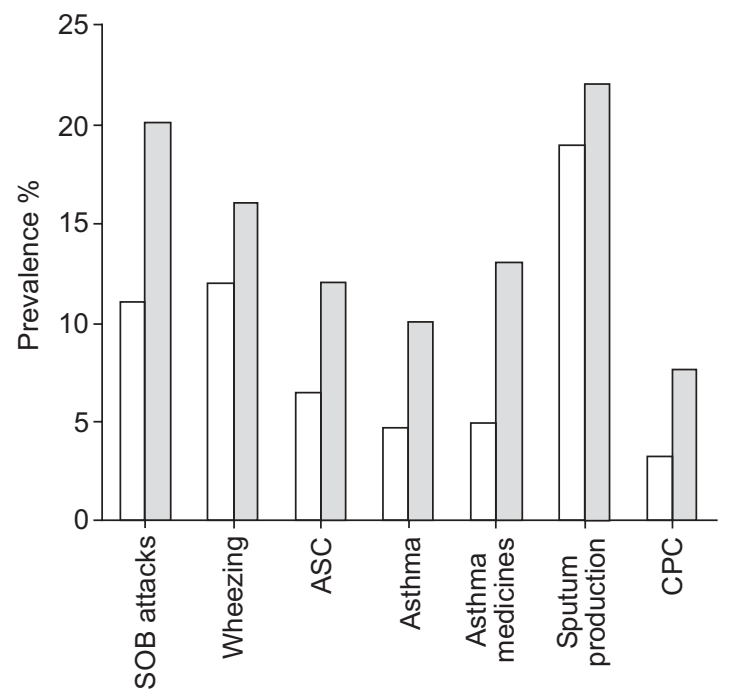

FIGURE 1. Prevalence of asthma, respiratory symptoms and asthma medicines in $1986(\square)$ and $1996(\square)$. SOB: shortness of breath; ASC: asthmatic symptom complex; CPC: chronic productive cough. $p<0.001$ for all variables. smokers, persistent ex-smokers and quitters were all significantly associated with incident users of asthma medicines, attacks of shortness of breath, recurrent wheeze, the asthmatic symptom complex and chronic productive cough. Age was a significant risk factor for incidence of chronic productive cough but not for asthma or other symptoms (table 6).

\section{DISCUSSION}

After correction for age, sex, family history of asthma, smoking habits and occupational exposure to dust, gases or fumes, the risk of developing asthma was increased among manual workers in industry. The risk of developing wheeze was increased among manual workers in industry and also among manual workers in service. The incidence of asthma was lowest in the socio-economic group consisting of professionals. This was also true for attacks of shortness of breath and wheezing, symptoms common in asthma. This is interesting, as asthma has often been regarded as a disease most common in the middle and upper classes [2]. The present results are in accordance with a recently published study from Norway, which found low educational level to be strongly associated with asthma and respiratory symptoms [9].

The contribution of manual workers in industry and service in terms of population attributable risks for incident chronic productive cough, asthma and symptoms common in asthma was $7-12 \%$.

Previous cross-sectional studies examining the relation of asthma and airway disorders to socio-economic status have not been able to present a consistent pattern. The divergent findings may be a result of differences in study design, varying definitions of socio-economic status, the age distributions of the studied samples, differences in exposures, occupational and otherwise, and geographical aspects. Generally, studies in Nordic countries have found more symptoms or asthma [5, 23], lower lung function [24] or a greater prevalence of chronic obstructive pulmonary disease $[25,26]$ in lower SECs. The present results confirm those of previously performed cohort studies, one of Nordic adults [9] and the other of US adolescents [10]. The present study exemplifies the limitation with a cross-sectional study when examining risks. It showed that manual work in industry was related to the development of asthma and symptoms. However, this could not be shown in 

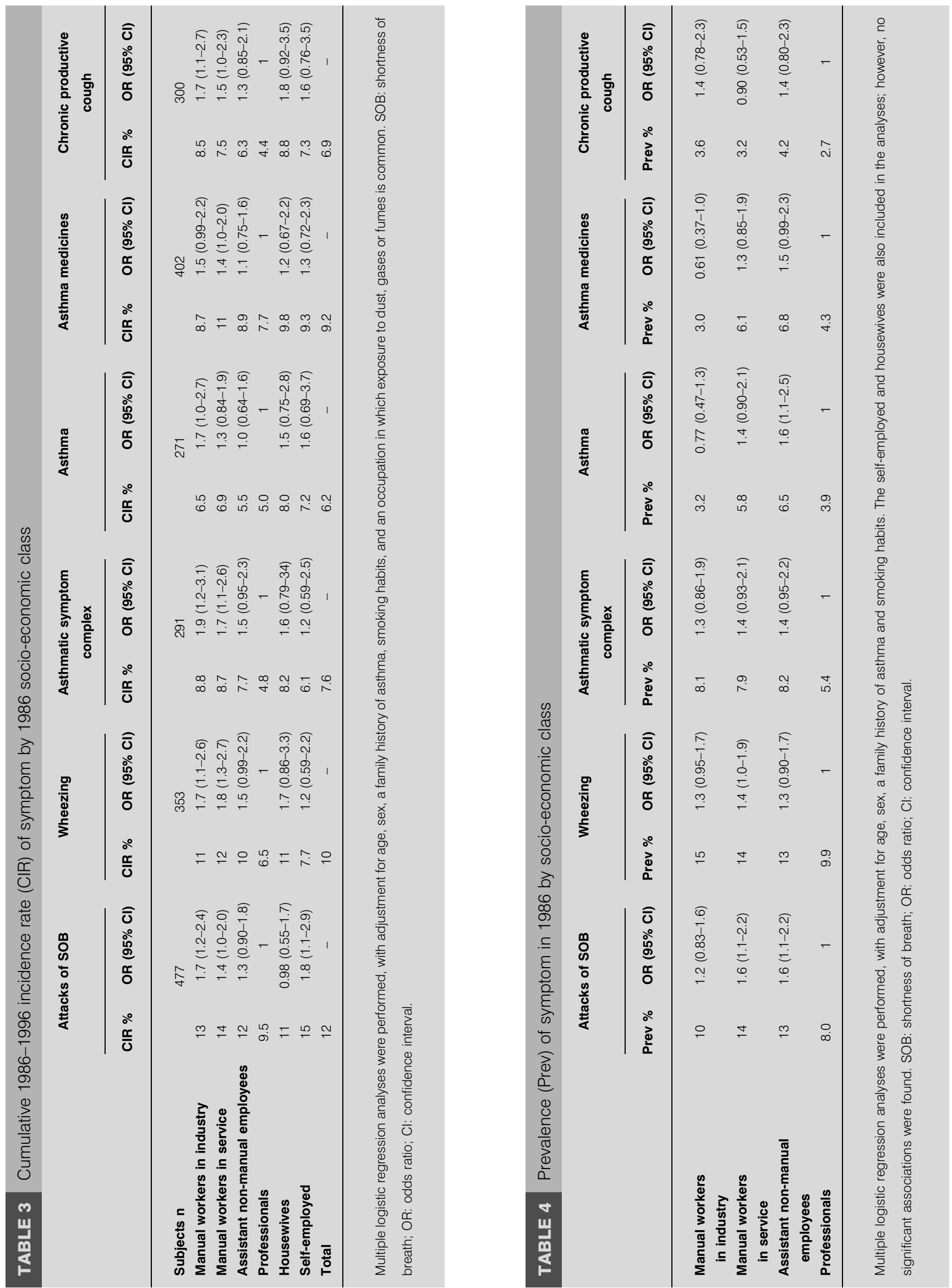
TABLE 5 Population attributable risks for manual workers in industry and service by 1986 socio-economic class

\begin{tabular}{lllclll} 
& Attacks of SOB & Wheezing & Asthmatic symptom complex & Asthma & Asthma medicines & Chronic productive cough \\
\hline Industry & $8.9(3.6-13)$ & $9.0(2.0-13)$ & $11(3.9-16)$ & $8.8(0-14)$ & $6.5(-0.20-11)^{\#}$ & $10(2.2-16)$ \\
Service & $7.6(0-13)$ & $12(6.3-17)$ & $11(2.4-17)$ & $6.1(-5.1-13)$ & $8.3(0-15)$ & $8.7(0-15)$ \\
\hline
\end{tabular}

Data are presented as \% (95\% confidence interval). SOB: shortness of breath. ${ }^{\#}: p=0.055$ for corresponding odds ratio.

the cross-sectional setting, probably due to a healthy worker effect, i.e. subjects with asthma may not choose a job in industry and, furthermore, would probably move from work in industry if they develop asthma.

Some of the strengths of the present study design are the longitudinal data collection, large sample size, high participation rate and a $10-y r$ observation period. Thus sufficient power has been obtained such that the bias caused by non-response can be considered to be limited. The effects of nonresponse have previously been studied. Non-response was associated with low socio-economic status, and the nonresponders had a somewhat higher prevalence of respiratory symptoms [27]. Thus it can be considered that bias caused by non-response may have decreased the influence of manual workers on the incidence of asthma and symptoms.

The overall incidence of asthma was relatively high in the present study. In a previous report on asthma incidence, an attempt was made to evaluate to what extent the incidence of physician-diagnosed asthma reflects its true incidence and what represents increased awareness of asthma and increased diagnostic activity, although, after several corrections, the annual incidence of asthma was still 2-3 per thousand population [14].

Some studies have used educational level as the indicator of socio-economic status [9]. The present study used a socioeconomic classification system based on occupation [19]. The classification based on occupation reflects educational level, as well as income, quite well, whereas there are limits in defining socio-economic status by educational level alone. A common length of schooling among the subjects in the oldest age group (born 1919-1920) was 6-9 yrs. This length corresponds to 912 yrs, the most common in the youngest age group (born 1949-1950). Thus it is believed that the classification system used in the present study is advantageous. However, with these categories, housewives could not be classified in different socio-economic groups, which is why they constituted one entity in the analyses. The high incidence of asthma and symptoms among housewives is notable but not unexpected, since it also could reflect a sex effect, as the majority was female. Housewives represent a heterogeneous group from a socio-economic point of view, including, among others,

TABLE 6 Risk factors for respiratory symptoms and asthma

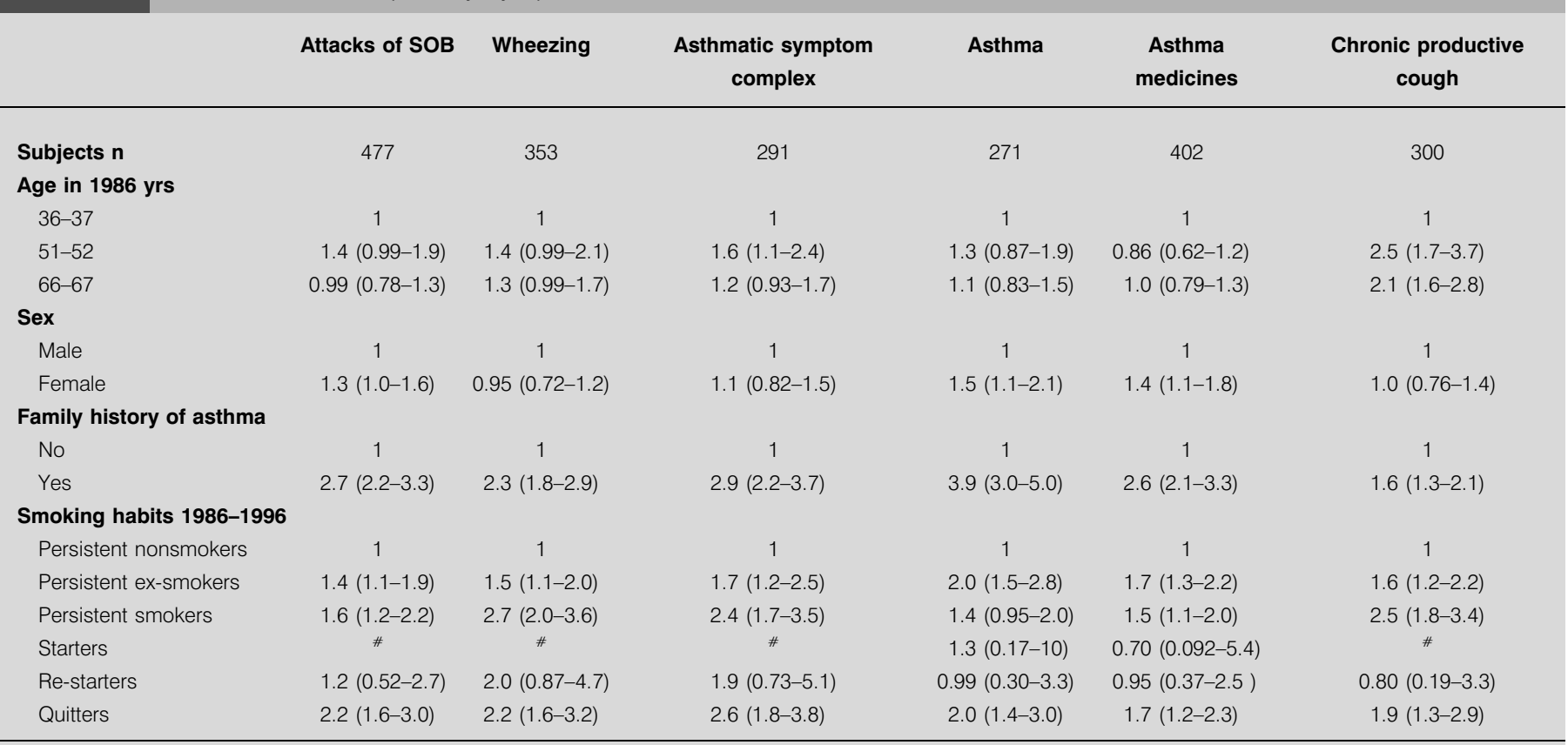

Data are presented as odds ratio (95\% confidence interval), unless otherwise indicated. Multiple logistic regression analyses were performed; other variables included in the model were socio-economic class and occupational exposure to dust, gases or fumes. SOB: shortness of breath; * : too few cases. 
females living on farms and, mainly, elderly females, probably belonging to the manual working classes. Furthermore, as in the Norwegian cohort [20], the incidence of asthma was highest among females, which, to a great extent, explains this finding.

There are a number of possible confounders, including lifestyle factors, such as smoking habits, diet, physical activity, body mass index and occupational exposure, that may be of importance, and corrections have been made for several of them. Occupational exposure to dust and fumes may contribute to the increased risk among manual workers [20, 23, 28]. In the study of EAGAN et al. [9], exposure to dust and fumes was accounted for, and the results showed a slightly decreased risk associated with educational level. Both current and previous smoking were important risk factors. This is in line with a report that reviewed the effect of smoking cessation. This found that the prevalence of respiratory symptoms remained higher in ex-smokers for many years compared with nonsmokers [29]. Passive smoking is associated with asthma and respiratory symptoms $[17,30]$, and it is disappointing that data about passive smoking were not available. However, smoking was more common among manual workers, which is why passive smoking was probably also more common in this group and could contribute to the increased risk of asthma and respiratory symptoms.

Obesity in Sweden is somewhat unevenly distributed by socioeconomic status, and obesity increases the risk of incident asthma among adults, both male and female, irrespective of atopic status [31]. Differences in diet between SECs may also be relevant. A low intake of fresh fruit, vegetables and fish is associated with increased respiratory symptoms and lower lung function [32, 33]. A poor dwelling environment, with exposure to dampness, mould, mites, gas cooking and nitrogen dioxide, may be harmful $[34,35]$. However, there are no mites in Northern Sweden [36] and gas cooking hardly exists. Access to healthcare must be regarded as being more or less evenly distributed across the different socio-economic groups in Northern Sweden. Nevertheless, access to healthcare, identification of asthma and classification of disease may, to some extent, have contributed to the results. However, poorer access to healthcare in lower SECs is hardly a major explanation of the results; this is supported by the results showing a high incidence of users of asthma medicines among manual workers in both industry and service workers.

In conclusion, the present study is one of a very few longitudinal studies investigating the association between socio-economic status and asthma and respiratory symptoms. Low socio-economic status was a risk factor for the development of asthma and symptoms common in asthma, as well as for chronic productive cough, with population attributable risks of $\sim 10 \%$. There is probably a multifactorial cause for this relationship. In order to explore these associations, it is necessary to identify the responsible factors using a longitudinal study design.

\section{ACKNOWLEDGEMENTS}

The Obstructive Lung Disease in Northern Sweden Studies staff, particularly A-C. Jonsson, are hereby acknowledged for collecting data. The authors thank B. Lundbäck for valuable comments about the manuscript.

\section{REFERENCES}

1 Mackenbach JP, Kunst AE, Cavelaars AE, Groenhof F, Geurts JJ. Socioeconomic inequalities in morbidity and mortality in Western Europe. The EU Working Group on Socioeconomic Inequalities in Health. Lancet 1997; 349: 1655-1659.

2 Viegi V, Annesi I, Matteelli G. Epidemiology of asthma. Eur Respir Mon 2003; 23: 1-25.

3 Peat JK, Woolcock AJ, Leeder SR, Blackburn CR. Asthma and bronchitis in Sydney schoolchildren. II. The effect of social factors and smoking on prevalence. Am J Epidemiol 1980; 111: 728-735.

4 Kaplan BA, Mascie-Tayor CG. Asthma and wheezy bronchitis in adolescents: biosocial correlates. J Asthma 1988; 25: 125-129.

5 Bakke PS, Hanoa R, Gulsvik A. Educational level and obstructive lung disease given smoking habits and occupational airborne exposure: a Norwegian community study. Am J Epidemiol 1995; 141: 1080-1088.

$6 \mathrm{Ng}$ Man Kwong G, Das C, Proctor AR, Whyte MK, Primhak RA. Diagnostic and treatment behaviour in children with chronic respiratory symptoms: relationship with socioeconomic factors. Thorax 2002; 57: 701-704.

7 Mitchell EA, Stewart AW, Pattemore PK, Asher MI, Harrison AC, Rea HH. Socioeconomic status in childhood asthma. Int J Epidemiol 1989; 18: 888-890.

8 Ernst P, Demissie K, Joseph L, Locher U, Becklake MR. Socioeconomic status and indicators of asthma in children. Am J Respir Crit Care Med 1995; 152: 570-575.

9 Eagan TM, Gulsvik A, Eide GE, Bakke PS. The effect of educational level on the incidence of asthma and respiratory symptoms. Respir Med 2004; 98: 730-736.

10 Beckett WS, Jacobs DR Jr, Yu X, Iribarren C, Williams OD. Asthma is associated with weight gain in females but not males, independent of physical activity. Am J Respir Crit Care Med 2001; 164: 2045-2050.

11 Liberatos P, Link BG, Kelsey JL. The measurement of social class in epidemiology. Epidemiol Rev 1988; 10: 87-121.

12 Lundbäck B, Nyström L, Rosenhall L, Stjernberg N. Obstructive lung disease in Northern Sweden: respiratory symptoms assessed in a postal survey. Eur Respir J 1991; 4: 257-266.

13 Rönmark E, Jönsson E, Lundbäck B. Remission of asthma in the middle aged and elderly: report from the Obstructive Lung Disease in Northern Sweden study. Thorax 1999; 54: 611-613.

14 Lundbäck B, Rönmark E, Jönsson E, Larsson K, Sandström T. Incidence of physician-diagnosed asthma in adults - a real incidence or a result of increased awareness? Report from The Obstructive Lung Disease in Northern Sweden Studies. Respir Med 2001; 95: 685-692.

15 Mikaelsson B, Stjernberg N, Wiman LG. The prevalence of bronchial asthma and chronic bronchitis in an industrialized community in Northern Sweden. Scand J Soc Med 1982; 10: 11-16.

16 Medical Research Council's committee on the aetiology of chronic bronchitis. Standardised questionnares on respiratory symptoms. BMJ 1960; ii: 1665.

17 Larsson ML, Loit HM, Meren M, et al. Passive smoking and respiratory symptoms in the FinEsS Study. Eur Respir J 2003; 21: 672-676. 
18 Lundbäck B, Stjernberg N, Rosenhall L, Lindström M, Jönsson E, Andersson S. Methacholine reactivity and asthma. Report from the Northern Sweden Obstructive Lung Disease Project. Allergy 1993; 48: 117-124.

19 Statistics Sweden. The Socio-Economic Classification of Occupations. Stockholm, Statistics Sweden, 1982.

20 Eagan TM, Bakke PS, Eide GE, Gulsvik A. Incidence of asthma and respiratory symptoms by sex, age and smoking in a community study. Eur Respir J 2002; 19: 599-605.

21 Anon. Nordisk Yrkesklassificering. Svensk Grundstandard. [Nordic Occupational Classification. Swedish Base Standard.] Stockholm, Labour Market Board, 1983.

22 Rothman KJ, Greenland S. Modern Epidemiology. 2nd Edn. Philadelphia, PA, Lippincott-Raven, 1998.

23 Bakke S, Baste V, Hanoa R, Gulsvik A. Prevalence of obstructive lung disease in a general population: relation to occupational title and exposure to some airborne agents. Thorax 1991; 46: 863-870.

24 Prescott E, Lange P, Vestbo J. Socioeconomic status, lung function and admission to hospital for COPD: results from the Copenhagen City Heart Study. Eur Respir J 1999; 13: 1109-1114.

25 Isoaho R, Puolijoki H, Huhti E, Kivela SL, Laippala P, Tala E. Prevalence of chronic obstructive pulmonary disease in elderly Finns. Respir Med 1994; 88: 571-580.

26 Lundbäck B, Lindberg A, Lindström M, et al. Not 15 but $50 \%$ of smokers develop COPD? Report from the Obstructive Lung Disease in Northern Sweden Studies. Respir Med 2003; 97: 115-122.

27 Rönmark E, Lundqvist A, Lundbäck B, Nyström L. Nonresponders to a postal questionnaire on respiratory symptoms and diseases. Eur J Epidemiol 1999; 15: 293-299.

28 Trupin L, Earnest G, San Pedro M, et al. The occupational burden of chronic obstructive pulmonary disease. Eur Respir J 2003; 22: 462-469.
29 Willemse BW, Postma DS, Timens W, ten Hacken NH. The impact of smoking cessation on respiratory symptoms, lung function, airway hyperresponsiveness, and inflammation. Eur Respir J 2004; 23: 464-476.

30 Janson C, Chinn S, Jarvis D, Zock JP, Toren K, Burney P. Effect of passive smoking on respiratory symptoms, bronchial responsiveness, lung function, and total serum $\mathrm{IgE}$ in the European Community Respiratory Health Survey: a cross-sectional study. Lancet 2001; 358: 2103-2109.

31 Rönmark E, Andersson C, Nyström L, Forsberg B, Järvholm B, Lundbäck B. Obesity increases the risk of incident asthma among adults. Eur Respir J 2005; 25: 282-288.

32 Peat JK, Salome CM, Woolcock AJ. Factors associated with bronchial hyperresponsiveness in Australian adults and children. Eur Respir J 1992; 5: 921-929.

33 Schwartz J, Weiss ST. Dietary factors and their relation to respiratory symptoms. The Second National Health and Nutrition Examination Survey. Am J Epidemiol 1990; 132: 67-76.

34 Bornehag CG, Blomquist G, Gyntelberg F, et al. Dampness in buildings and health. Nordic interdisciplinary review of the scientific evidence on associations between exposure to "dampness" in buildings and health effects (NORDDAMP). Indoor Air 2001; 11: 72-86.

35 Chauhan AJ, Krishna MT, Frew AJ, Holgate ST. Exposure to nitrogen dioxide $\left(\mathrm{NO}_{2}\right)$ and respiratory disease risk. Rev Environ Health 1998; 13: 73-90.

36 Perzanowski MS, Rönmark E, Nold B, Lundbäck B, PlattsMills TA. Relevance of allergens from cats and dogs to asthma in the northernmost province of Sweden: schools as a major site of exposure. J Allergy Clin Immunol 1999; 103: 1018-1024. 